\title{
$\mathrm{RF}$-プラズマ法による $\mathrm{SiC}, \mathrm{Si}_{3} \mathrm{~N}_{4}$ 粉体の合成
}

\author{
柊平啓・光井彰・北條純一・加藤昭夫 \\ (九州大学 工学部 応用化学科)
}

\section{Preparation of $\mathrm{SiC}$ and $\mathrm{Si}_{3} \mathrm{~N}_{4}$ Powders by RF-Plasma}

\author{
Akira KUIBIRA, Akira MITSUI, Junichi HOJO and Akio KATO
}

(Department of Applied Chemistry, Faculty of Engineering, Kyushu University

Hakozaki, Higashi-ku, Fukuoka-shi 812

By the RF-plasma method, preparation of silicon carbide and silicon nitride powders from alkoxysilanes $\left(\mathrm{Si}\left(\mathrm{OC}_{2} \mathrm{H}_{5}\right)_{4}\right.$, $\left(\mathrm{CH}_{3}\right)_{2} \mathrm{Si}\left(\mathrm{OC}_{2} \mathrm{H}_{5}\right)_{2}$ and $\left.\left(\mathrm{CH}_{3}\right)_{2} \mathrm{Si}\left(\mathrm{OCH}_{3}\right)_{2}\right)$ and from $\mathrm{SiCl}_{4}-\mathrm{NH}_{3}$ system, respectively, was studied. In the preparation of silicon carbide, the reaction product consisted of $\beta$-SiC, free carbon and silicon oxide. The amount of $\mathrm{SiC}$ in the powder product increased with rising reaction temperature or with increasing $\left[\mathrm{H}_{2}\right]$. The amount of $\mathrm{SiC}$ increased with decreasing C/Si ratio in alkoxysilanes and was estimated to reach $100 \%$ when the C/Si ratio is around 3. In the preparation of silicon nitride, the reaction product was white and non-crystalline powders with a particle size of 0.01-0.02 $\mu \mathrm{m}$. The composition of powders was virtually independent of $\left[\mathrm{NH}_{3}\right]$ and close to that of $\mathrm{Si}_{3} \mathrm{~N}_{4}$. Heat treatment at $1550^{\circ} \mathrm{C}$ was necessary to obtain the crystalline $\alpha-S i_{3} N_{4}$.

[Received July 14, 1986]

Key-words : RF-plasma, Alkoxysilanes, Silicon carbide, Silicon nitride, Powders

\section{1. 緒 言}

$\mathrm{SiC}, \mathrm{Si}_{3} \mathrm{~N}_{4}$ は強度, 耐食性, 耐熱衝撃性に優れた高 温材料であるが，焼結が困難であり，焼結性に優れた原 料粉体の合成法が活発に研究されている。 その一つに高 温プラズマを用いる方法がある. $\mathrm{SiCl}_{4}$ を原料とした $\mathrm{RF}$-プラズマ法による $\mathrm{SiC}$ 粉体の合成についてはすで に報告した ${ }^{1)}$. 本報では, $\mathrm{SiCl}_{4}$ より安価な $\mathrm{SiO}_{2}$-炭化 水素系からプラズマ気相反応による $\mathrm{SiC}$ 粉体の製造の 可能性を調べる目的で, Si-O-C 系のモモデル物質として 3 種のアルコキシシラン $\left(\mathrm{Si}\left(\mathrm{OC}_{2} \mathrm{H}_{5}\right)_{4}, \quad\left(\mathrm{CH}_{3}\right)_{2} \mathrm{Si}\right.$ $\left.\left(\mathrm{OC}_{2} \mathrm{H}_{5}\right)_{2},\left(\mathrm{CH}_{3}\right)_{2} \mathrm{Si}\left(\mathrm{OCH}_{3}\right)_{2}\right)$ 力ら $\mathrm{SiC}$ 粉体の合成を 行い, 反応条件の影響を調べた。また, $\mathrm{SiCl}_{4}-\mathrm{NH}_{3}$ 系 から四塩化ケイ素のアンモニア付加物をプラズマフレー ム中へ供給する方法による $\mathrm{Si}_{3} \mathrm{~N}_{4}$ 粉体の一段合成も試み た.

\section{2. 実 験}

\section{$2.1 \mathrm{SiC}, \mathrm{Si}_{3} \mathrm{~N}_{4}$ 粉体の合成}

図1AにRF-プラズマ反応器の構造を示す。電源には 国際電気製 $4 \mathrm{MHz}, 4 \mathrm{~kW}$ 高周波発振機 NU-410A を用 い，3.5 kW で使用した。プラズマガスには $\mathrm{Ar}$ を用い, 反応ガスはプラズマ炎の下部に供給した。

$\mathrm{SiC}$ 合成の場合, 反応ガス導入管は一重（径 $8 \mathrm{~mm}$, シリカガラス製) または二重 (外管径 $8 \mathrm{~mm}$, シリカガ ラス製, 内管径 $2 \mathrm{~mm}$, ステンレス製; 原料が $\mathrm{Si}\left(\mathrm{OC}_{2} \mathrm{H}_{5}\right)_{4}$ の場合）のものを用いた. $\mathrm{Si}\left(\mathrm{OC}_{2} \mathrm{H}_{5}\right)_{4}$ は原料液をステ
ンレス管からマイクロフィーダーを用いて供給し，反応 ガス導入管中で蒸発させ $\mathrm{H}_{2}$ ガスと共にフレーム中に供 給じた。 $\left(\mathrm{CH}_{3}\right)_{2} \mathrm{Si}\left(\mathrm{OC}_{2} \mathrm{H}_{5}\right)_{2}$ 及び $\left(\mathrm{CH}_{3}\right)_{2} \mathrm{Si}\left(\mathrm{OCH}_{3}\right)_{2}$ は 蒸発器よりアルゴンをキャリアとして運び, 水素と混合 してフレーム中に供給した，図 1 の $h$ (反応ガス導入位 置を示す）は，ワークコイル下端から反応ガス導入管ま での距離で, この $h$ を変えると反応ガスの加熱温度が 変わり結果に大きな影響を与える. 本研究では $h$ を 4 種類かえて実験した.

$\mathrm{Si}_{3} \mathrm{~N}_{4}$ 合成の場合, 反応ガス導入管を図 $1 \mathrm{~B}$ に示した 二重管構造（シリカガラス製）とした. $\mathrm{SiCl}_{4}$ と $\mathrm{NH}_{3}$ は常温でも反応して付加物を生成する. 本研究では, 導

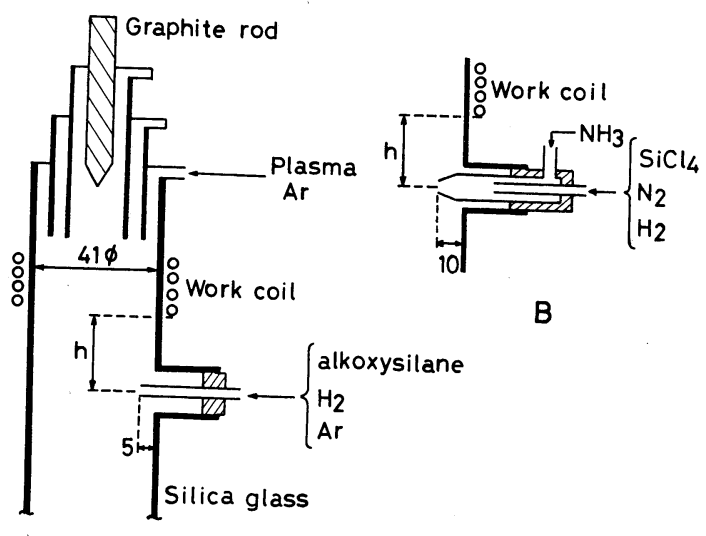

A

Fig. 1. RF-plasma reactor. 
入部内で $\mathrm{SiCl}_{4}$ と $\mathrm{NH}_{3}$ を混合し, 生成した粉体流をフ レーム中へ供給した. 反応ガス導入位置 $h$ は $3.5 \mathrm{~cm}$ と した. また, 副生物の $\mathrm{NH}_{4} \mathrm{Cl}$ は $\mathrm{Ar}$ 気流中 $450^{\circ} \mathrm{C}, 3$ 時 間加熱除去した.

\section{2 生成物の分析}

生成粉体の同定は粉末 X線回折 (Co $K \alpha)$ により行っ た. $\mathrm{SiC}$ 合成反応の生成物は酸素雾囲気中 $1200^{\circ} \sim$ $1300^{\circ} \mathrm{C}$ で完全に酸化し, 発生する $\mathrm{CO}_{2}$ を定量すること により全 $\mathrm{C}$ 量を, 残存する $\mathrm{SiO}_{2}$ から全 $\mathrm{Si}$ 量を求め, $\mathrm{Si}$ 及びC 分以外を酸素分 $(\Delta m)$ とした。 そして酸素 は $\mathrm{SiO}_{2}$ として存在し生成物中には $\mathrm{Si}$ は生成しないと して， $\mathrm{SiC}, \mathrm{C}, \mathrm{SiO}_{2}$ 量を見積もった。一方， $\mathrm{Si}_{3} \mathrm{~N}_{4}$ 合 成では, $\mathrm{Si}$ 分は $\mathrm{SiC}$ の場合と同様に重量法により, $\mathrm{N}$

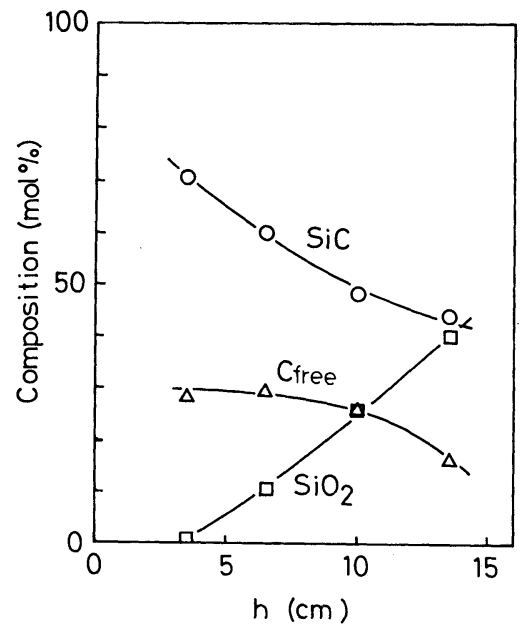

Fig. 2. Effect of position of introduction of reactant gases on composition of product. Plasma $\mathrm{Ar}=15 \mathrm{l}$ $\min ,\left[\left(\mathrm{CH}_{3}\right)_{2} \mathrm{Si}\left(\mathrm{OCH}_{3}\right)_{2}\right]=0.051 \mathrm{vol} \%,\left[\mathrm{H}_{2}\right]=8.8$ vol\%.

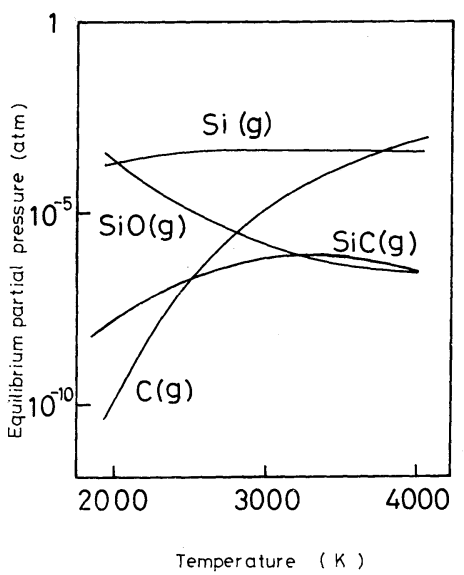

Fig. 3. Equilibrium partial pressures of important species for $\left[\left(\mathrm{CH}_{3}\right)_{2} \mathrm{Si}\left(\mathrm{OCH}_{3}\right)_{2}\right]_{0}=5.1 \times 10^{-4} \mathrm{~atm} ;\left[\mathrm{H}_{2}\right]_{0}$ $=8.8 \times 10^{-2}$ atm $\left(\mathrm{JANAF}^{2}\right.$ data were used for calculation).
分はアルカリ溶融を用いたケルダール法により求めた.

\section{3. 結果と考察}

\section{$3.1 \mathrm{SiC}$ の合成}

生成物の結晶相はX線回折では 3 種の原料とも $\beta-\mathrm{SiC}$ のみであった。他の生成物はX線回折では観測できな かった．図 2 に $\left(\mathrm{CH}_{3}\right)_{2} \mathrm{Si}\left(\mathrm{OCH}_{3}\right)_{2}$ を原料に用いた場合 の反応ガス導入位置 $h$ の効果を示す. $h$ が小さくなる ほよ゙，反応ガスの温度が高くなり，生成粉体中の $\mathrm{SiC}$ 及び Cの分率は増加し, $\mathrm{SiO}_{2}$ の分率は減少した.この 傾向は，他の二つの原料でも同様であった. $\mathrm{SiC}, \mathrm{SiO}_{2}$, C の生成に関係すると考えられる $\mathrm{Si}(\mathrm{g}), \operatorname{SiC}(\mathrm{g}), \mathrm{SiO}$ $(\mathrm{g}), \mathrm{C}(\mathrm{g})$ の平衡分圧を図 3 に示す. $\mathrm{SiC}(\mathrm{s})$ が生成

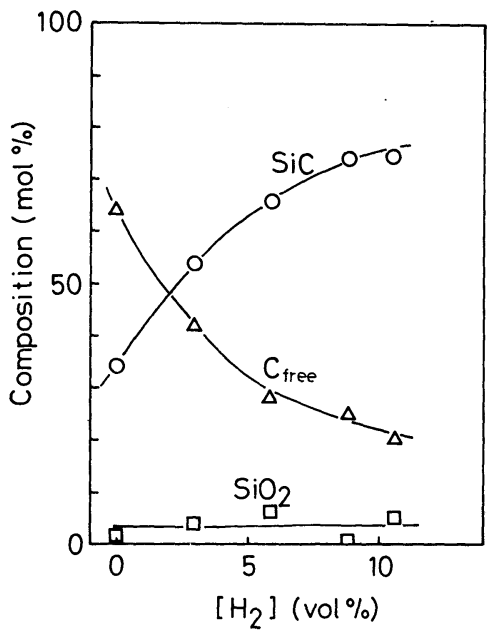

Fig. 4. Effect of $\mathrm{H}_{2}$ concentration on composition of product. Plasma $\mathrm{Ar}=15 \mathrm{l} / \mathrm{min},\left[\left(\mathrm{CH}_{3}\right)_{2} \mathrm{Si}\left(\mathrm{OCH}_{3}\right)_{2}\right]=$ $0.034 \mathrm{vol} \%, h=3.5 \mathrm{~cm}$.

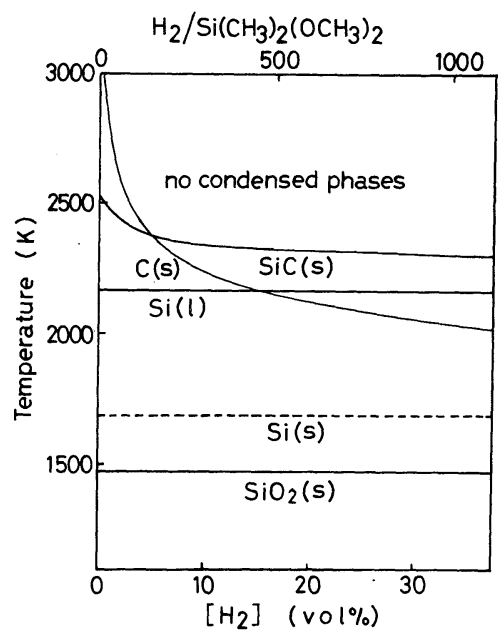

Fig. 5. Deposition temperature of condensed phase. $\left[\left(\mathrm{CH}_{3}\right)_{2} \mathrm{Si}\left(\mathrm{OCH}_{3}\right)_{2}\right]_{0}=0.034 \mathrm{vol} \%\left(\mathrm{JANAF}^{2)}\right.$ data were used for calculation). 


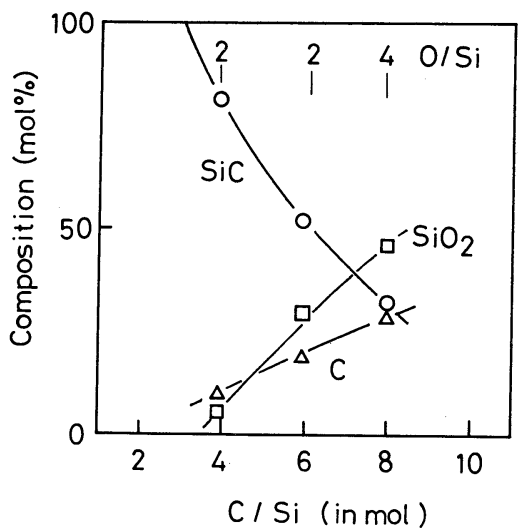

Fig. 6. Effect of $\mathrm{C} / \mathrm{Si}$ ratio of alkoxysilanes on composition of product. $\left[\mathrm{H}_{2}\right] /$ [alkoxysilanes] $=200, h=$ $3.5 \mathrm{~cm}$.

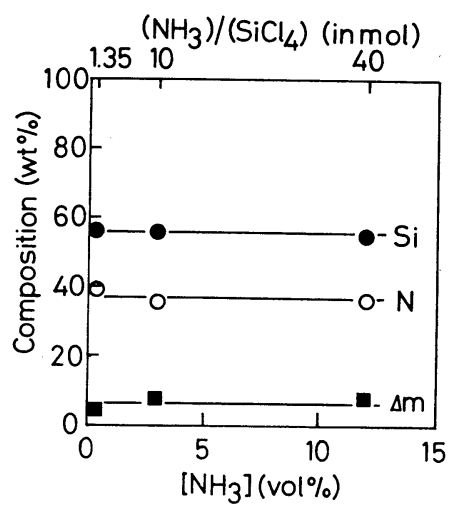

Fig. 7. Effect of $\mathrm{NH}_{3}$ concentration on chemical composition of product. Plasma $\mathrm{Ar}=5 \mathrm{l} / \mathrm{min},\left[\mathrm{SiCl}_{4}\right]=$ $0.3 \mathrm{vol} \%$.

する $3000 \mathrm{~K}$ 以下の領域では, 高温ほど $\mathrm{SiC}(\mathrm{g})$ 及び $\mathrm{C}(\mathrm{g})$ の分圧は増加し, $\mathrm{SiO}(\mathrm{g})$ の分圧は減少する.この傾向 は図 2 の生成粉体の組成の変化の傾向とよく一致してい る. 図 4 に $\left(\mathrm{CH}_{3}\right)_{2} \mathrm{Si}\left(\mathrm{OCH}_{3}\right)_{2}$ を原料に用いた場合の水 素濃度の効果を例示する. 水素濃度が減少すると Cの分 率が急激に増加した. 図 5 に気相反応系が平衡にある時 の各凝縮相の生成領域を示す．図中の曲線は気相におけ る平衡分圧と各固相あるいは液相の飽和蒸気圧が等しく なる温度で, 曲線の下側の温度でそれらの析出が可能と なる．水素濃度が減少すれば遊離炭素の生成領域は高温 部まで広がり, 水素濃度の減少によって C が多量に生成 することが説明できる. 図 5 中の $\mathrm{SiO}_{2}$ の生成温度は $\mathrm{SiO}$ の不均化反応 $\left[2 \mathrm{SiO}(\mathrm{g}) \rightarrow \mathrm{SiO}_{2}(\mathrm{~s})+\mathrm{Si}(\mathrm{s})\right]$ を考 えた場合で, 析出温度は $\mathrm{SiC}$ や Cに比べかなり低温で
ある.これらの結果からプラズマ反応管中では冷却過程 でまず $\mathrm{SiC}$ や C が生成し, $\mathrm{SiO}_{2}$ の生成は最後に起こる と考えられる.

図 6 に原料中の $\mathrm{C} / \mathrm{Si}$ 比と生成粉体の組成との関係を まとめた．原料中の $\mathrm{C} / \mathrm{Si}$ 比が小さいほど $\mathrm{SiC}$ の生成 分率は増加し, $\mathrm{C}$ 及び $\mathrm{SiO}_{2}$ の分率は減少した. 外そう すると C/Si 比が 3 付近で $\mathrm{SiC}$ はほぼ $100 \%$ になる. このことから $\mathrm{SiO}_{2}$ 粉体をプラズマフレーム中に供給し て, 分解蒸発させ, その $\mathrm{CH}_{4}$ との反応によって $\mathrm{SiC}$ を 合成する場合, $\mathrm{CH}_{4}$ と $\mathrm{SiO}_{2}$ の供給比を 3 前後で反応さ せれば良いことが分かった。

\section{$3.2 \mathrm{Si}_{3} \mathrm{~N}_{4}$ の合成}

生成物は白色の非晶質粉体であり, TEM 観察より粒 径は $0.01 \sim 0.02 \mu \mathrm{m}$ であった. 図 7 に $\mathrm{NH}_{3}$ 濃度と生成 粉体の組成との関係を示す. 図中の $\Delta m$ は $\mathrm{Si}$ 分及び $\mathrm{N}$ 分以外で不純物酸素と考えられる. 四塩化ケイ素のアン モニア付加物を熱分解する本方法 [(1)，（2）式]では 生成物の組成は $\mathrm{NH}_{3}$ 濃度によってほとんど変化せず, しかも $\mathrm{Si}_{3} \mathrm{~N}_{4}$ に近い $\mathrm{Si}, \mathrm{N}$ 含有量を示した.

$$
\begin{aligned}
& \mathrm{SiCl}_{4}(\mathrm{~g})+\mathrm{NH}_{3}(\mathrm{~g}) \rightarrow \mathrm{SiCl}_{4} \cdot n \mathrm{NH}_{3}(\mathrm{~s}) \\
& \mathrm{SiCl}_{4} \cdot n \mathrm{NH}_{3}(\mathrm{~s}) \rightarrow \mathrm{Si}_{3} \mathrm{~N}_{4}(\mathrm{~s})
\end{aligned}
$$

生成粉体を $2 \mathrm{t} / \mathrm{cm}^{2}$ で成形したペレットを窒素中 $1450^{\circ} \sim 1550^{\circ} \mathrm{C}, 2$ 時間熱処理した. $1500^{\circ} \mathrm{C}$ 以下では結

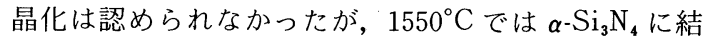
晶化し粒子は約 $2 \mu \mathrm{m}$ の球形粒子に成長した. 熱処理で の重量減少は $3.6 \mathrm{wt} \%\left(1450^{\circ} \mathrm{C}\right), 4.6 \mathrm{wt} \%\left(1500^{\circ} \mathrm{C}\right)$ および 19.8 wt $\%\left(1550^{\circ} \mathrm{C}\right)$ で, 結晶化が進む $1550^{\circ} \mathrm{C}$ での重量減少が大きな值となった。この重量減少量は表 面酸化物と窒化ケイ素の反応による $\mathrm{SiO}, \mathrm{N}_{2}$ ガスの発 生でほぼ説明できる.

$$
\mathrm{Si}_{3} \mathrm{~N}_{4}(\mathrm{~s})+3 \mathrm{SiO}_{2}(\mathrm{~s}) \rightarrow 6 \mathrm{SiO}(\mathrm{g})+2 \mathrm{~N}_{2}(\mathrm{~g}) \text { ( } 3 \text { ) }
$$

結晶化過程での著しい粒成長も $\mathrm{SiO}(\mathrm{g})$ を介して起こ ると考えられるので, 生成粉体中の酸素量（空気中での 取り扱い中の表面酸化によると考えられる）を減少させ れば, 粒成長は抑制できよう.しかし, 目的とした結晶 性 $\mathrm{Si}_{3} \mathrm{~N}_{4}$ 粉体の一段合成は, プラズマ法を用いても困難 である。

謝 辞 本研究に対し, 武田科学振興財団研究助成金を受 けた．記して謝意を表する。

\section{文 献}

1) 光井 彰, 加藤昭夫, 窯協, 94, 517-20 (1986).

2) “JANAF 熱化学データ集”, 堀越研究所 (1965-1968) No. 1-6. 